\title{
CD73 Is Regulated by the EGFR-ERK Signaling Pathway in Non-small Cell Lung Cancer
}

\author{
SEBASTIAN GRIESING ${ }^{1}$, BIN-CHI LIAO ${ }^{2}$ and JAMES CHIH-HSIN YANG ${ }^{1,2,3}$ \\ ${ }^{1}$ Department of Oncology, National Taiwan University Hospital, Taipei, Taiwan, R.O.C.; \\ ${ }^{2}$ National Taiwan University Cancer Center, College of Medicine, \\ National Taiwan University, Taipei, Taiwan, R.O.C.; \\ ${ }^{3}$ Graduate Institute of Oncology, College of Medicine, National Taiwan University, Taipei, Taiwan, R.O.C.
}

\begin{abstract}
Background/Aim: Successful therapy of EGFRmutant NSCLC remains a challenging task despite initial benefits with the usage of EGFR tyrosine kinase inhibitors. Cancer immunotherapy has shown promising results in certain tumors, but response rate in EGFR-mutant NCLC is low, because these tumors are thought to have weak immunogenicity. Materials and Methods: We used data from in vivo NSCLC databases as well as from in vitro cell culture experiments to investigate the regulation of CD73 by EGFR. Results: EGFR expression was correlated with CD73 expression in patients' datasets, with EGFR-mutant tumors showing higher expression than their EGFR wildtype counterparts. Treatment of EGFRmutant NSCLC cell lines with EGFR TKI reduced expression of CD73 at both mRNA and protein level. Among EGFR downstream signaling pathways, the Ras-Raf-ERK pathway was involved in the regulation of CD73 expression directly via ERK1/2 without the engagement of RSKs or MSKs. Conclusion: The results of this study may provide novel therapeutic strategies for the treatment of oncogene-driven NSCLC.
\end{abstract}

With more than 1.5 million deaths worldwide, lung cancer remains the leading cause of cancer-related deaths, despite major progresses in lung cancer research and therapy. Tumors with activating mutations in the epidermal growth factor receptor $(E G F R)$ gene are frequently observed in nonsmall lung cancer (NSCLC) patients in East Asia (1). These mutations lead to autophosphorylation of EGFR and subsequent activation of down-stream signaling pathways,

This article is freely accessible online.

Correspondence to: James Chih-Hsin Yang, MD, Ph.D., National Taiwan University, Department of Oncology, No.7, Chung Shan S. Rd., Zhongzheng Dist., Taipei City 100, Taiwan, R.O.C. Tel: +886 0223123456 (ext.66589), e-mail: chihyang@ntu.edu.tw

Key Words: CD73, EGFR, ERK1/2, oncogene-driven NSCLC. including the MAPK cascade (Ras-Raf-ERK), the PI3KAKT signaling pathway and the JAK/STAT signaling pathway, all of which contribute to cell growth and -survival (2). EGFR-tyrosine kinase inhibitor (EGFR TKI) therapy is effective in treating patients with activating EGFR mutation, but despite initial response, the median progression-free survival (PFS) is only 9-13 months and acquired resistance is inevitable (3-7). Thus, the development of novel therapy approaches is as important as ever. In recent years, cancer immunotherapy has gained wide attention, with successful application in the treatment of melanoma and renal cancer $(8,9)$. In contrast, EGFR-mutant NSCLC do not respond well to checkpoint inhibitor therapy, because they are thought to possess weak immunogenicity and immunological ignorance (10-13). However, the underlying mechanisms remain unclear and poorly understood.

CD73, a GPI-anchored membrane protein widely expressed on tumor cells, is an important enzyme in the conversion of adenosine monophosphate (AMP) to adenosine and organic phosphate. Adenosine activates $\mathrm{A}(2 \mathrm{~A})$ receptors and creates an immunosuppressive niche by inhibiting the activation and function of macrophages, neutrophils, dendritic cells and Tcells $(14,15)$. Accumulating evidence suggests that nonimmunomodulating functions of CD73 play an equally important role for cancer cell survival, progression and migration (16-21). Elevated expression of CD73 is frequently observed in solid tumors and high CD73 expression was reported to be an indicator of poor prognosis in NSCLC and other cancers $(22,23)$. Targeting CD73 as a potential cancer treatment has so far focused on the inhibition of its immunomodulatory functions in the context of rendering immunologically "cold" tumors sensitive to treatment with checkpoint inhibitors (24). However, the prognostic role of CD73 and its role of predicting response to immune checkpoint inhibitor monotherapy is still controversial.

Expression of CD73 in cancer has been shown to be increased under hypoxic conditions by HIF-1 $\alpha$ (25), as well as by the activation of the NFKB- and Wnt/ $\beta$-catenin 
Table I. Drugs used in this study.

\begin{tabular}{llr}
\hline Name & Purchased from & Working concentration \\
\hline ZD1839 (gefitinib) & Adooq Bioscience, Irvine, CA, USA & $20 \mathrm{nM}$ \\
BIBW 2992 (afatinib) & Adooq Bioscience, Irvine, CA, USA & $20 \mathrm{nM}$ \\
AZD9291 (osimertinib) & Adooq Bioscience, Irvine, CA, USA & $20 \mathrm{nM}$ \\
AZD6244 (selumetinib) & Adooq Bioscience, Irvine, CA, USA & $1 \mu \mathrm{M}$ \\
MK-2206 & Adooq Bioscience, Irvine, CA, USA & $1 \mu \mathrm{M}$ \\
INCB018424 (ruxolitinib) & Adooq Bioscience, Irvine, CA, USA & $1 \mu \mathrm{M}$ \\
U0126 & Adooq Bioscience, Irvine, CA, USA & $10 \mu \mathrm{M}$ \\
BVD-523 (ulixertinib) & Adooq Bioscience, Irvine, CA, USA & $1 \mu \mathrm{M}$ \\
LJH685 & Adooq Bioscience, Irvine, CA, USA & $10 \mu \mathrm{M}$ \\
SB747641A & Adooq Bioscience, Irvine, CA, USA & $10 \mu \mathrm{M}$ \\
GDC-0994 (ravoxertinib) & Adooq Bioscience, Irvine, CA, USA & $1 \mu \mathrm{M}$ \\
\hline
\end{tabular}

signaling pathways $(26,27)$. However, the regulation of basal CD73 expression in NSCLC and the relationship with EGFR and its downstream signaling pathways remains vague. In the present study, we show that expression of CD73 is directly regulated by the Ras-Raf-ERK pathway on transcriptional level, and that this regulation is mediated by ERK1/2 in both EGFR-mutant as well as KRAS-mutant cell lines. These findings may provide novel therapeutic strategies for the treatment of NSCLC with driver oncogene.

\section{Materials and Methods}

Cell culture. The HCC827 and NCI-H441 lung adenocarcinoma cell lines were purchased from American Type Culture Collection (ATCC; Manassas, VA, USA). All cell lines were grown in Roswell Park Memorial Institute (RPMI-1640; Cytiva, Marlborough, MA, USA) supplemented with 10\% Fetal Bovine Serum (FBS; Gibco, Carlsbad, CA, USA), 2 mM L-Glutamine and 1x Antibiotic-Antimycotic Solution (all Corning, New York, NY, USA), and maintained at $37^{\circ} \mathrm{C}$ in a humidified atmosphere containing $5 \% \mathrm{CO}_{2}$. Medium was replaced with fresh medium every two days and cells were sub-cultured when reaching about $90 \%$ confluency to ensure optimal conditions for experiments. EGFR mutation status was confirmed by Sanger sequencing.

Drug treatment and establishment of afatinib-resistant PC-9 cell line. Origin and working concentrations of all drugs used in this study can be found in Table I. For drug treatment of cells, $2 \times 10^{5}$ cells were seeded into $6 \mathrm{~cm}$ dishes and grown for $48 \mathrm{~h}$ before medium was replaced with fresh medium containing the drug of interest. After $48 \mathrm{~h}$ incubation time, cells were washed once with ice-cold Phosphate Buffered Saline (PBS; Cytiva) and subsequently lysed with $200 \mu$ l Radioimmunoprecipitation Assay Buffer (RIPA; Cell Signaling, Danvers, MA, USA), supplemented with protease and phosphatase inhibitors (Thermo Fischer Scientific, Waltham, MA, USA), or $350 \mu \mathrm{l}$ TRI Reagent (Zymo Research, Irvine, CA, USA) for isolation of protein and RNA, respectively. Afatinibresistant PC-9 cells (PC-9-AR) were established by growing parental PC-9 cells in escalating concentrations of afatinib (starting from $0.1 \mathrm{nM}$ ) for six months. The occurrence of T790M mutation as a resistance mechanism was confirmed by Sanger sequencing.
Western blot analysis. Protein concentration was measured using a Bradford Protein Assay Kit (Sigma, St. Louis, MO, USA). A total of $20 \mu \mathrm{g}$ of protein were then subjected to SDS-PAGE on a $10 \%$ polyacrylamide gel and subsequently blotted on a Hybond Nitrocellulose Membrane (Cytiva, Marlborough, MA, USA). After air-dry for $1 \mathrm{~h}$, membranes were blocked in 5\% milk in Tris-buffered Saline $+0.1 \%$ Tween (TBST; Omics Bio, New Taipei City, Taiwan) for $1 \mathrm{~h}$ at room temperature and subsequently probed with the indicated primary (at $4^{\circ} \mathrm{C}$ overnight) and secondary antibodies (at room temperature, $1 \mathrm{~h}$ ). Following washes with TBST, membranes were developed using Immobilon Western Chemiluminescent Horseradish Peroxidase (HRP) Substrate (Millipore, Billerica, MA, USA). All antibodies used in this study were purchased from Cell Signaling Technology (Danvers, MA, USA).

Quantitative reverse transcription polymerase chain reaction ( $q R T$ $P C R$ ). RNA was extracted from cells using an RNA Isolation Kit (Zymo Research) and subsequently quantified using NanoDrop (Thermo Fischer Scientific). 500 ng RNA were reverse transcribed into cDNA using PrimeScript RT Reagent Kit (Takara, Kusatsu, Japan). For qRT-PCR analysis, 10 ng cDNA were mixed with $5 \mu$ KAPA SBYR Green (Roche, Basel, Switzerland) and $500 \mathrm{nM}$ of gene-specific primers and amplification was performed on a StepOnePlus Real-Time PCR System (Thermo Fisher Scientific). Expression of each gene was normalized to $18 \mathrm{~S}$ and GAPDH expression levels, and calculated using the comparative $\mathrm{Ct}$ method. Primers were designed to span exon-exon junctions, when possible, to avoid background amplification from genomic DNA. Primer Sequences used were: GAPDH-F: 5'TGGTATCGTGGAAGGACTCATGAC-3', GAPDH-R: 5'-ATGCCA GTGAGCTTCCCGTTCAGC-3', 18S-F: 5'-AATCAGGGTTCGAT TCCGGA-3', 18S-R: 5'-CCAAGATCCAACTACGAGCT-3', CD73F: 5'-CAAAGAGGCCAAATTTCCAA-3', CD73-R: 5'-TTCCCA CAACTTCATCACCA-3'.

Cell viability assay. $1 \times 10^{3}$ cells were seeded into 96-well plates, treated with various concentration of afatinib (ranging from $0.1 \mathrm{nM}$ to $1 \mu \mathrm{M}$ ) and incubated for $96 \mathrm{~h}$ before cytotoxicity was determined using Sulforhodamine B (SRB) assay according to standard procedures. Cell viability was determined by dividing the absorbance values of treated cells to that of untreated cells. $\mathrm{IC}_{50}$ calculated from the dose response curve was defined as the concentration of afatinib which resulted in $50 \%$ growth inhibition. 


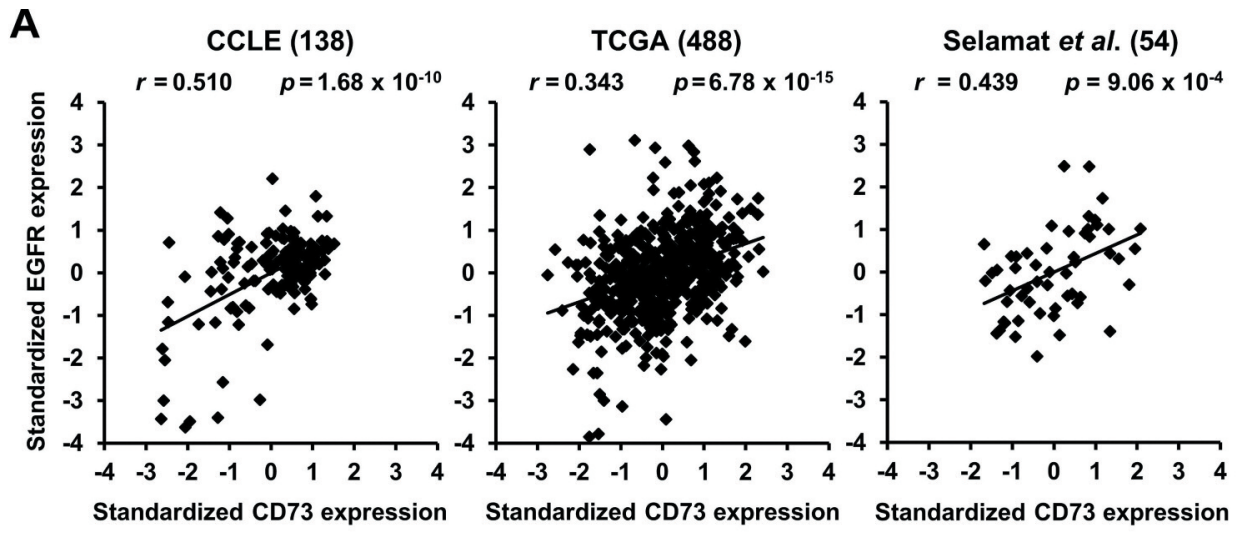

B

TCGA

Selamat et al.
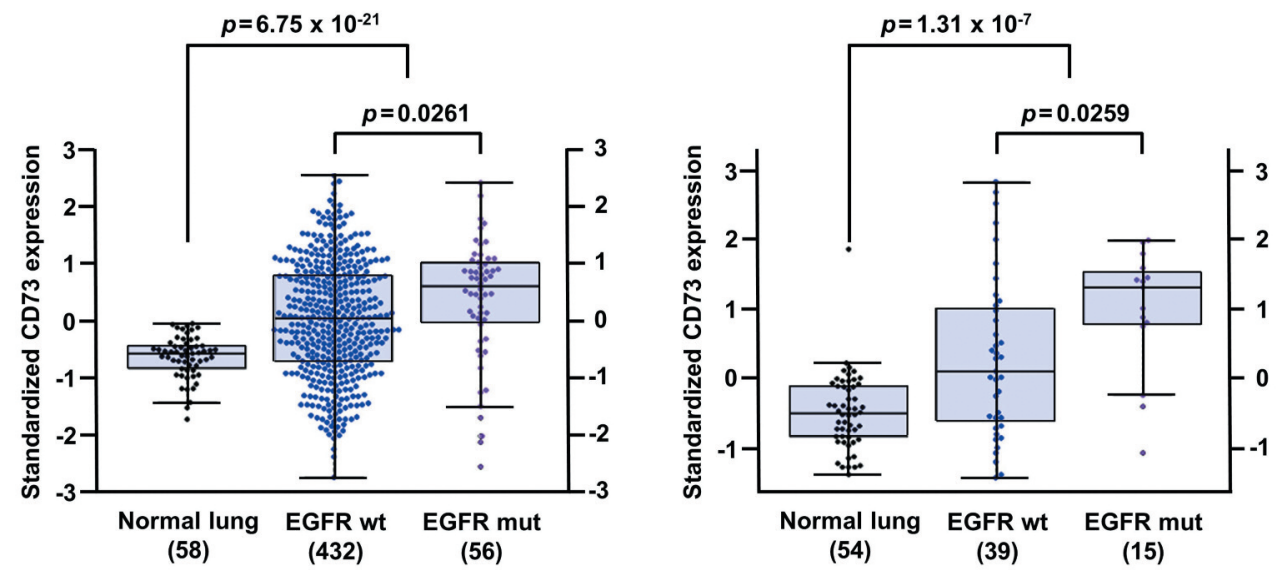

Figure 1. CD73 expression is correlated with expression of EGFR in NSCLC cells and patient samples. (A) Correlation analysis of CD73-and EGFR expression in three data sets. (B) Comparison of CD73 expression between normal lung, EGFR-wildtype and EGFR-mutant tumors in two NSCLC patient data sets. Expression is plotted as the log-normalized and Z-score standardized value of raw data ( $r$, correlation coefficient).

Statistics and data analyses. The Cancer Genome Atlas (TCGA) data was downloaded from the Genomic Data Commons Data Portal (GDC portal, https://portal.gdc.cancer.gov/), whereas The Cancer Cell Line Encyclopedia (CCLE) data was downloaded from the CCLE database (https://portals.broadinstitute.org/). Raw data was log transformed, followed by normalization using z-scores. All statistical analyses were done using Prism 5.0 (GraphPad Software Inc., La Jolla, San Jose, CA, USA), R or Microsoft Excel (Microsoft, Redmond, WA, USA). Statistical differences were then determined using two-tailed Student's $t$-test. Statistical significance was considered at a minimum value of $p<0.05$. All results presented represent the mean \pm SD of triplicate determinations of three independent experiments performed under the same conditions.

\section{Results}

Expression of CD73 correlates with EGFR expression in NSCLC patients. In order to investigate the relationship between the EGFR pathway and CD73 expression, we first analyzed their correlation in three data sets: the The Cancer Genome Atlas
(TCGA) data set (https://www.cancer.gov/tcga), comprising data from 488 NSCLC patients, a dataset published by Selamat et al. with data from 54 NSCLC patients (28), as well as the data set of the Cancer Cell Line Encyclopedia (CCLE), including data from 138 NSCLC cell lines (29). In all three data sets, expression of CD73 mRNA was significantly correlated with expression of EGFR mRNA (Figure 1A). Expression of CD73 mRNA was strongly elevated in tumor samples compared to normal lung tissue and expression was significantly higher in the EGFR-mutant subset compared to EGFR wildtype tumors (Figure 1B). Taken together, analysis of clinical data sets showed that CD73 expression correlated with expression of EGFR and is increased in NSCLC compared to normal lung with a higher expression in the EGFR-mutant group.

Treatment of EGFR-mutant NSCLC cell lines with EGFR TKIs decreased $m R N A$ - and protein expression of CD73. We next sought to investigate whether treatment of EGFR-mutant 
NSCLC cell lines with various EGFR TKIs would affect expression of CD73. Thus, we treated HCC827 and PC-9 cells, both harboring deletions in exon 19 of EGFR, with firstgeneration TKI gefitinib (30), second-generation TKI afatinib (31) and third-generation TKI osimertinib (32) and analyzed expression levels of CD73 mRNA by quantitative Reverse Transcription Polymerase Chain Reaction (qRT-PCR). In both cell lines, all three TKIs significantly reduced expression of CD73 mRNA (Figure 2A). Western blot analysis showed that reduction of $\mathrm{CD} 73$ expression was also observed on the protein level as all three TKIs strongly decreased protein expression of CD73 (Figure 2B). To rule out any off-target effects of the EGFR TKIs, we established an afatinib-resistant PC-9 cell line (PC-9-AR) by dose escalation protocol. PC-9AR cells displayed a high resistance to afatinib, as shown by a cell viability assay (Figure $2 \mathrm{C}$ ) with an $\mathrm{IC}_{50}$ of $132 \mathrm{nM}$, compared to $0.3 \mathrm{nM}$ of the parental PC-9 cell line. Sanger sequencing revealed that PC-9-AR cells acquired T790M mutation as a resistance mechanism (Figure 2D). Interestingly, PC-9-AR cells showed an increased expression of CD73 compared to PC-9 parental cells (Figure 2E), indicating an importance of CD73 in the survival of afatinib-resistant PC-9 cells. Increased expression of CD73 after EGFR TKI treatment has also been recently observed by Isomoto et al. (33). Treatment of PC-9-AR cells with EGFR TKIs showed that gefitinib treatment failed to decrease protein expression of CD73 (Figure 2F), whereas expression of CD73 was partially rescued in PC-9-AR cells compared to parental PC9 cells under afatinib treatment. In summary, we showed that EGFR TKIs could decrease mRNA and protein expression of CD73 in a specific manner, further strengthening the hypothesis that CD73 is regulated by the EGFR pathway.

Inhibition of the Ras-Raf-ERK signaling pathway, but not of the PI3K-AKT- or JAK/STAT- pathway decreased expression of $C D 73$. The EGFR pathway branches into three major downstream signaling pathways: the Ras-Raf-ERK-, the PI3KAKT-, and the JAK/STAT- signaling pathway, all of which fulfill distinct roles in the growth and survival of EGFR-mutant tumors $(2,34)$. Hence, we next investigated which of these EGFR downstream pathways regulates the expression of CD73. To this end, we treated HCC827-, PC-9 and PC-9-AR cells with selumetinib (35), MK-2206 (36) and ruxolitinib (37), inhibitors of the Ras-Raf-ERK-, PI3K-AKT- and JAK-STAT signaling pathway, respectively (Figure 3A). qRT-PCR analysis revealed that CD73 mRNA expression was significantly decreased in all cell lines treated with selumetinib (Figure 3B). In contrast, MK-2206 treatment increased mRNA expression of CD73, whereas ruxolitinib treatment had no effect on CD73 expression. The decrease of CD73 mRNA under selumetinib treatment was not due to altered half-life of CD73 mRNA since selumetinib did not affect degradation rate of CD73 mRNA in HCC827 cells, indicating regulation of CD73 mRNA on transcriptional level (data not shown). Protein expression of CD73 was also strongly decreased in selumetinib treated cells, similar to the decrease seen under osimertinib treatment (Figures 3C). On the contrary, MK-2206 treatment increased protein expression of CD73 in all cell lines, indicating distinct roles of the Ras-Raf-ERK pathway and the PI3K-AKT pathway in the regulation of CD73 expression in EGFR-mutant NSCLC. Efficiency of selumetinib, MK-2206 and ruxolitinib was confirmed by the inhibition of phosphorylation of ERK1/2 (T202/T204), AKT (S473) and STAT1 (Y701), respectively. In order to confirm the involvement of the Ras-Raf-ERK pathway in the positive regulation of CD73, we treated HCC827 and PC-9 cells with another commonly used inhibitor of the RasRaf-ERK pathway, U0126, and observed similar decrease in expression of CD73 protein (Figure 3D). Moreover, treatment of KRAS-mutant H441 cells with selumetinib, but not with MK-2206 or ruxolitinib, reduced CD73 protein levels (Figure $3 \mathrm{E})$, indicating that the regulation of CD73 by the Ras-RafERK pathway is also relevant in KRAS-mutant tumors. KRAS-mutant cells were shown to have elevated expression of CD73 $(38,39)$ and KRAS mutation was suggested to be associated with high expression of CD73 in cancer patients $(40$, 41). Taken together, these data show that expression of CD73 is positively regulated by the Ras-Raf-ERK pathway in EGFRand KRAS- mutant lung cancers.

ERK1/2, but not MSKs or RSKs, regulate the expression of $C D 73$. Signaling by the Ras-Raf-ERK pathway is moderated by three crucial mediators: the $90 \mathrm{kDa}$ ribosomal S6 kinases (RSKs), the mitogen- and stress-activated protein kinases (MSKs), both of which are directly phosphorylated and activated by ERK1/2, and ERK1/2 itself (42). Thus, we next sought to evaluate which ERK downstream mediator is involved in the regulation of CD73 expression. By that means, we treated HCC827-, PC-9 and PC-9-AR cells with ulixertinib (43), LJH685 (44) and SB747651A (45), inhibitors of ERK1/2, RSKs and MSKs, respectively (Figure 4A). Ulixertinib, but not LJH685 or SB747651A treatment significantly reduced expression of CD73 mRNA in all cell lines (Figure 4B). Expression of CD73 protein was similarly reduced in cell lines treated with ulixertinib (Figures $4 \mathrm{C}$ ), indicating that regulation of CD73 is mediated by ERK1/2 itself and not via activation of RSKs or MSKs. Efficiency of LJH685 and SB747651A was evaluated by inhibition of phosphorylation of RSK2 (S227) and CREB (S133), respectively. Interestingly, phosphorylation of ERK was increased rather than decreased in cell lines treated with ulixertinib (Figure 4C). It was reported previously that treatment with ulixertinib inhibited ERK kinase activity, but resulted in marked increase in MEK-mediated phosphorylation of ERK driven by the release of negative feedback signaling (43). We observed similar results by treatment of GDC-0994, another commonly used ERK inhibitor (46): GDC-0994 treatment decreased expression of CD73 in HCC827- and PC- 

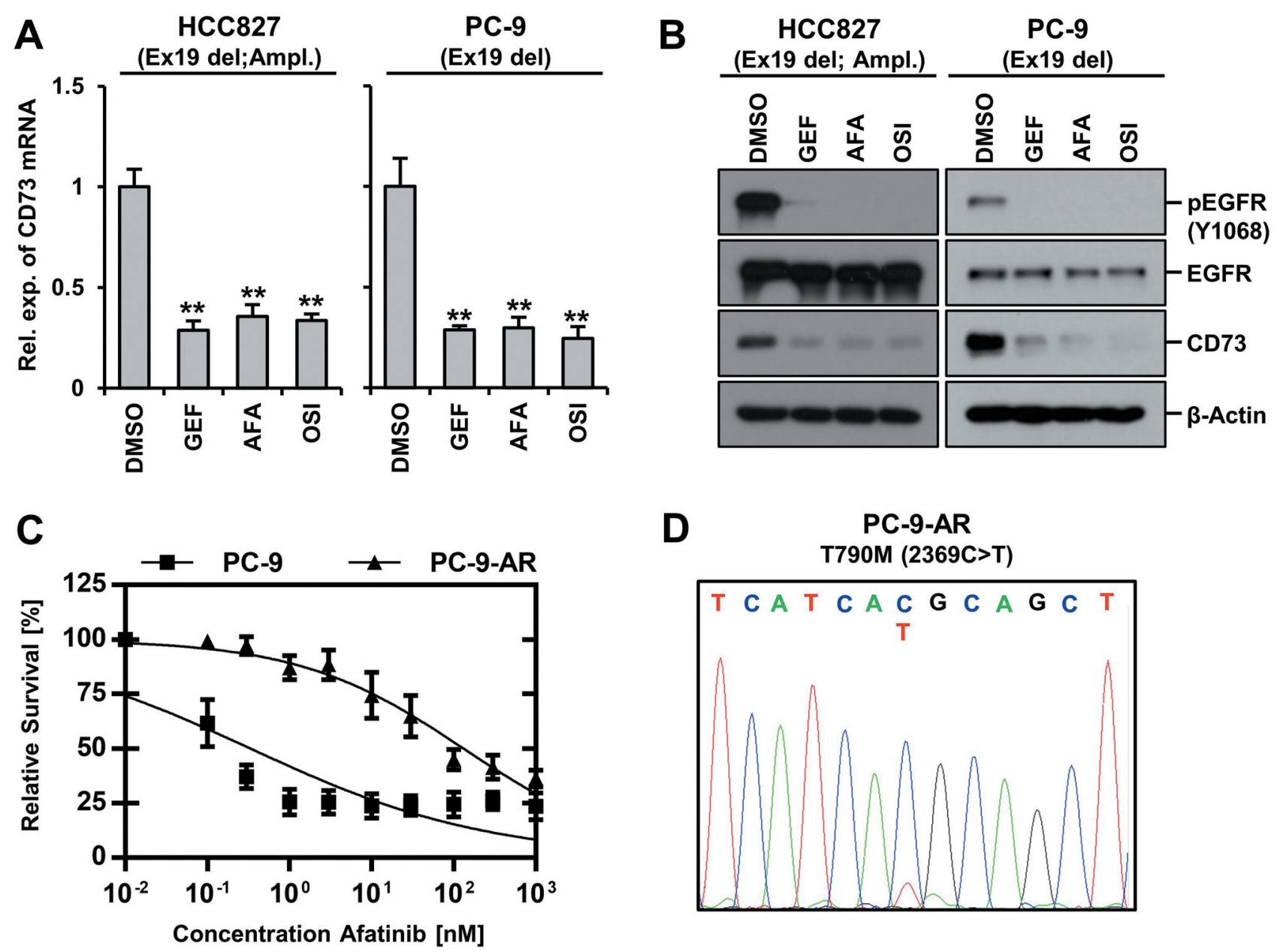

D

PC-9-AR

T790M (2369C>T)

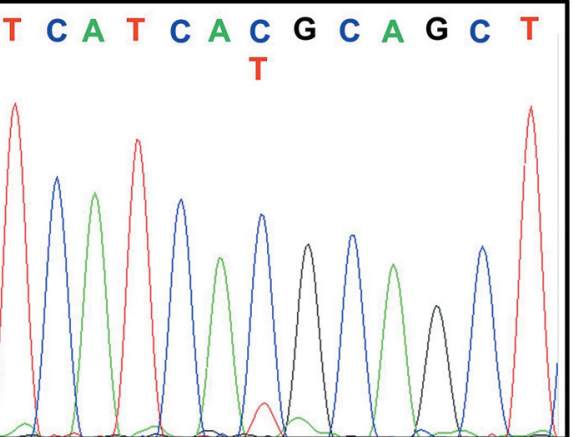

E

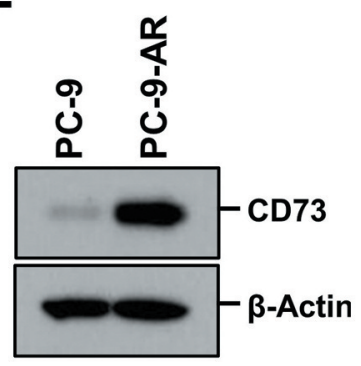

$\mathbf{F}$

PC-9-AR

(Ex19 del, T790M)

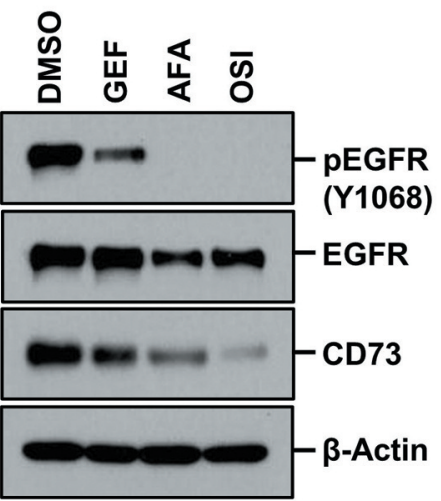

Figure 2. Treatment of EGFR-mutant NSCLC cell lines with EGFR TKIs decreases expression of CD73. (A) qRT-PCR analysis of CD73 mRNA expression in HCC827- and PC-9 cells after treatment with gefitinib (GEF), afatinib (AFA) and osimertinib (OSI). GAPDH and $18 S$ served as internal controls. (B) Western blot analysis of CD73 protein expression in HCC827- and PC-9 cells after treatment with EGFR TKIs. $\beta$-Actin served as an internal control. (C) Cell viability assay of PC-9 cells and afatinib-resistant PC-9 cells (PC-9-AR) at various concentrations of afatinib. (D) Sanger sequencing of EGFR Exon 20 in PC-9-AR cells showing occurrence of T790M. (E) Western blot analysis of CD73 protein expression in PC9 and PC-9-AR cells. $\beta$-Actin served as an internal control. $(F)$ Western bot analysis of CD73 protein expression in PC-9-AR cells after treatment with EGFR TKIs. $\beta$-Actin served as internal control. All experiments were carried out in triplicate and data shown represent mean $\pm S D$. ${ }^{*} p<0.05$; $* * p<0.01$, two-tailed Student's t-test. n.s., not significant. 

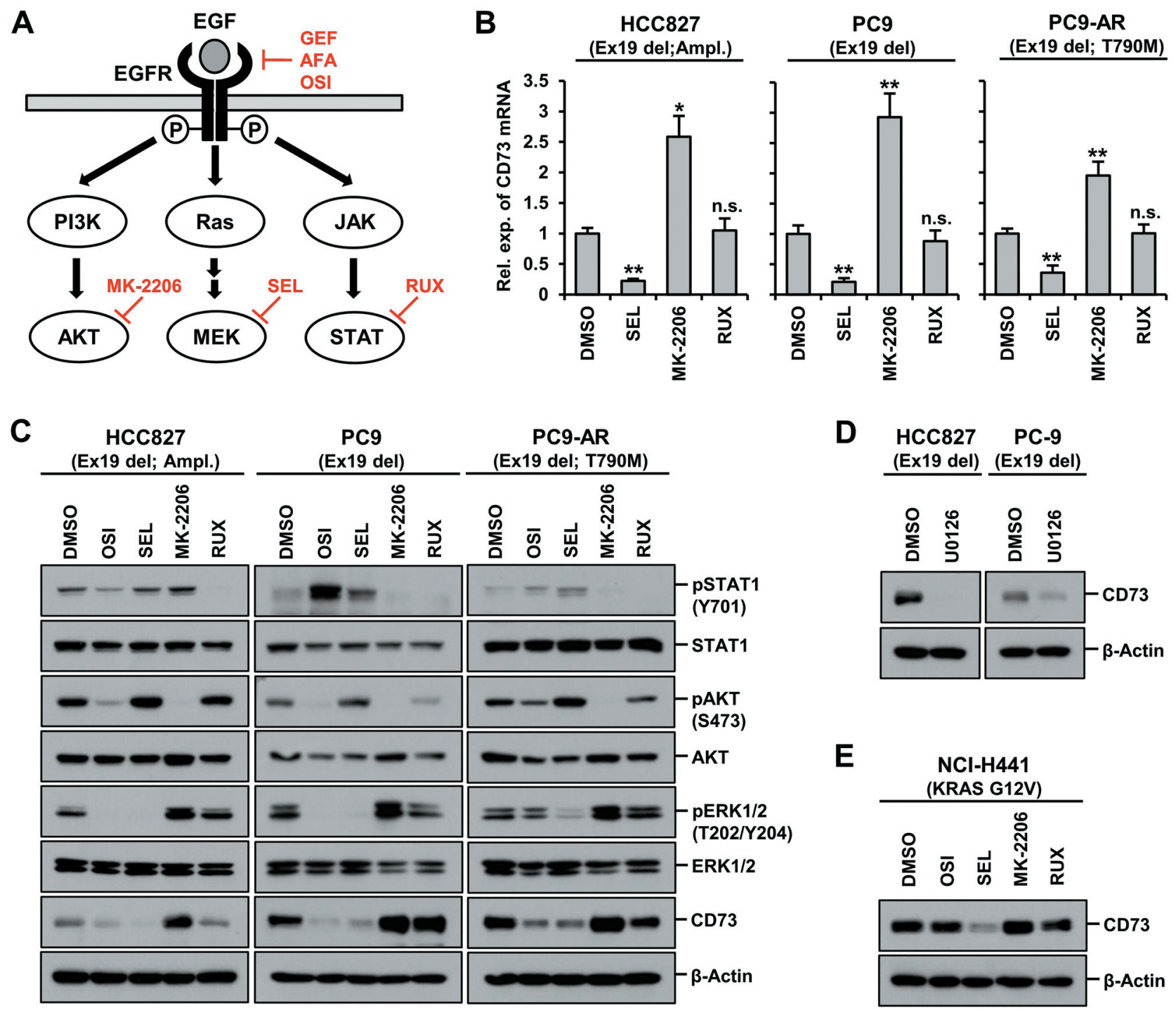

PC9-AR (Ex19 del; T790M)

\section{D}
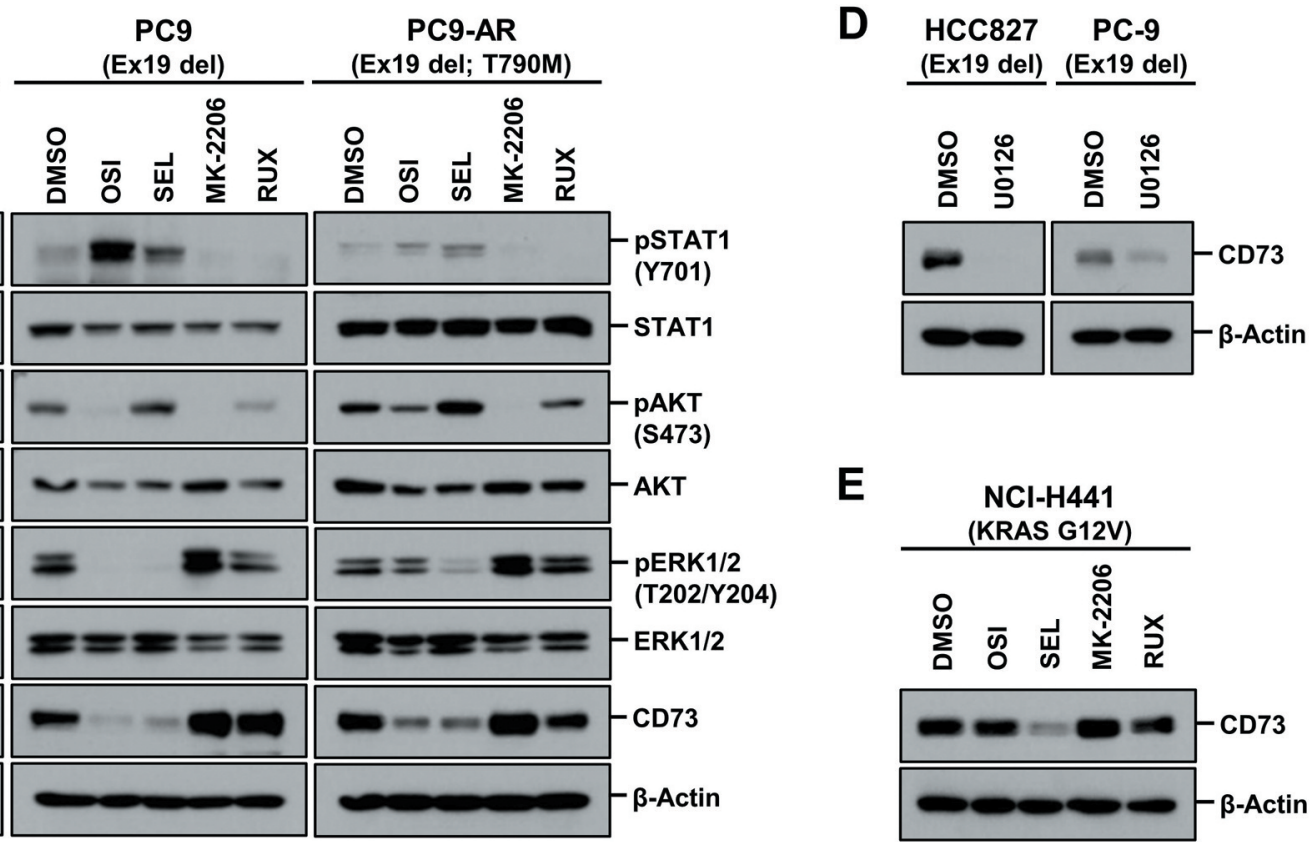

E

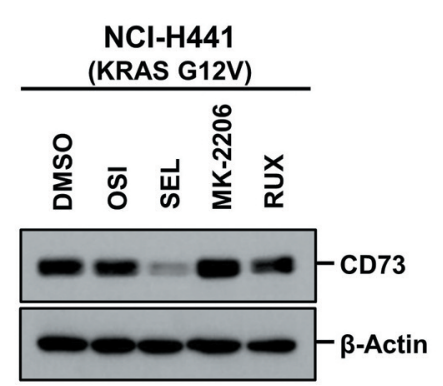

Figure 3. CD73 expression is regulated by the Ras-Raf-ERK pathway in EGFR-mutant NSCLC. (A) Schematic overview of EGFR downstream pathways and its inhibitors. (B) qRT-PCR analysis of CD73 mRNA expression in HCC827-, PC-9- and PC-9-AR cells after treatment with selumetinib (SEL), MK-2206 and ruxolitinib (RUX). GAPDH and 18 S served as internal controls. (C) Western blot analysis of CD73 protein expression in HCC827, PC-9- and PC-9-AR cells after treatment with SEL, MK-2206 and RUX. $\beta$-Actin served as an internal control. (D) Western blot analysis of CD73 protein expression of HCC827- and PC-9 cells after treatment with U0126. $\beta$-Actin served as internal control. (E) Western blot analysis of CD73 protein expression in KRAS-mutant H441 cells after treatment with SEL, MK-2206 and RUX. $\beta$-Actin served as an internal control. All experiments were carried out in triplicate and data shown represent mean $\pm S D .{ }^{*} p<0.05$; ${ }^{*} p<0.01$, two-tailed Student's t-test. n.s., not significant.

9 cells; however, phosphorylation of ERK was markedly increased (Figure 4D). In order to confirm that ERK kinase activity is indeed inhibited by ulixertinib, we investigated expression of two prominent ERK pathway target genes, DUSP6 (47) and FOS (48) by qRT-PCR. Ulixertinib significantly decreased mRNA expression of DUSP6 and FOS, similar to treatment with osimertinib and selumetinib, indicating successful inhibition of ERK1/2 by ulixertinib (data not shown). CD73 expression was also down-regulated in KRAS-mutant cell line H441 when treated with ulixertinib (Figure 4E), suggesting that ERK1/2-mediated regulation of CD73 expression also occurs in KRAS-mutant NSCLC cells. Collectively, we showed that regulation of $\mathrm{CD} 73$ expression in EGFR- and KRAS-mutant NSCLC is mediated downstream of the Ras-Raf-ERK pathway by ERK1/2 itself, rather than by engagement of RSKs and MSKs. These results could provide novel therapeutic strategies on how to inhibit CD73 expression in oncogene-driven NSCLC. 
A

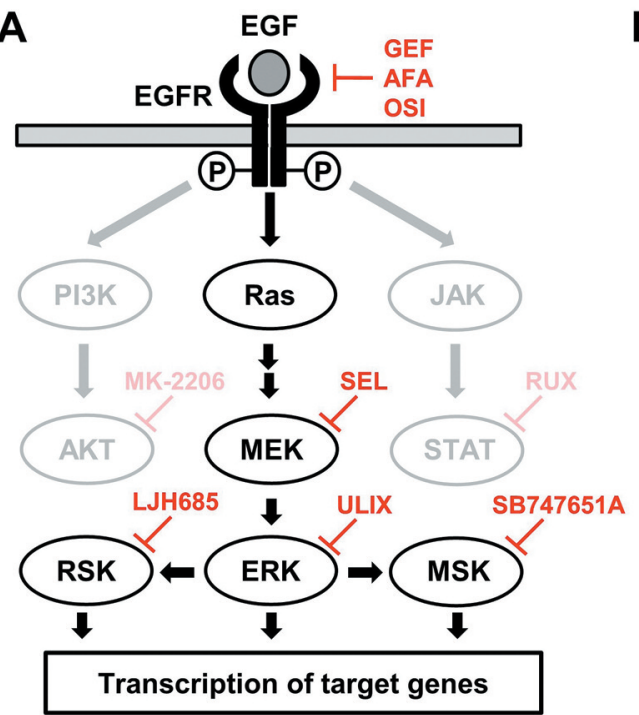

C
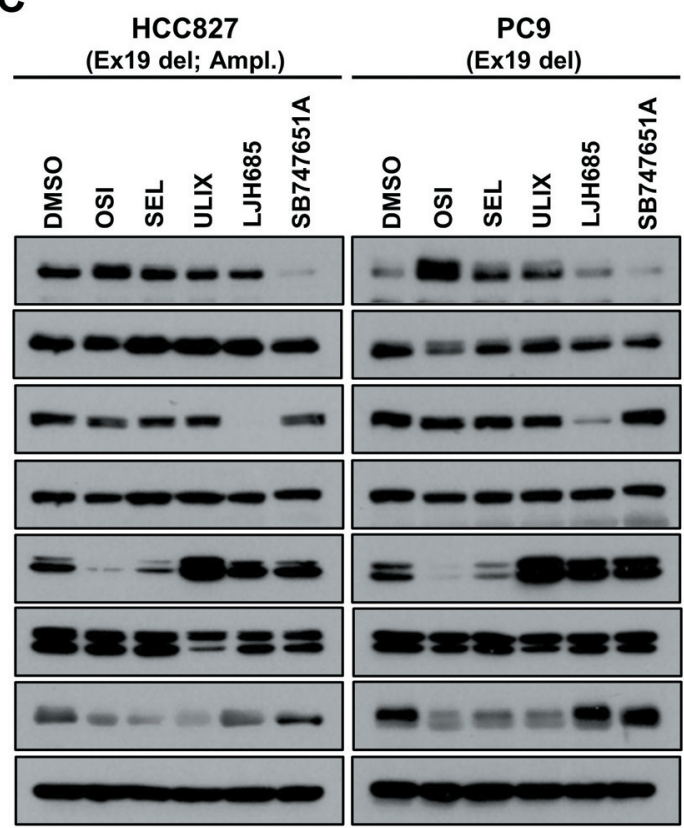

B

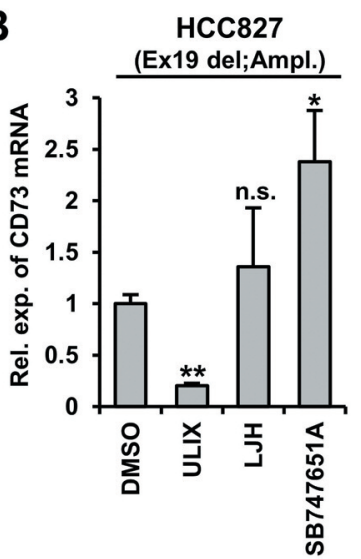

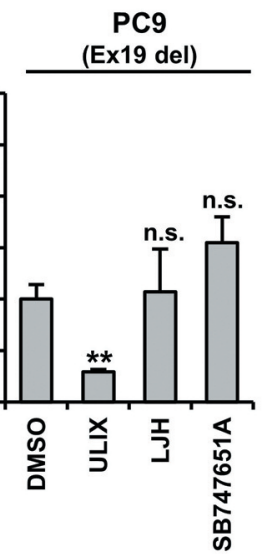

D
PC9-AR (Ex19 del; T790M)

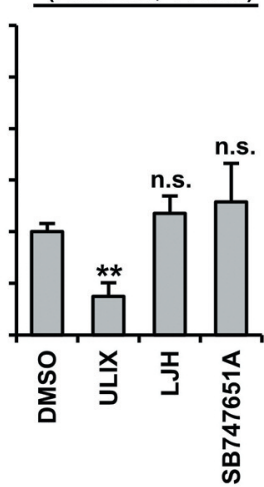

PC9-AR (Ex19 del, T790M)

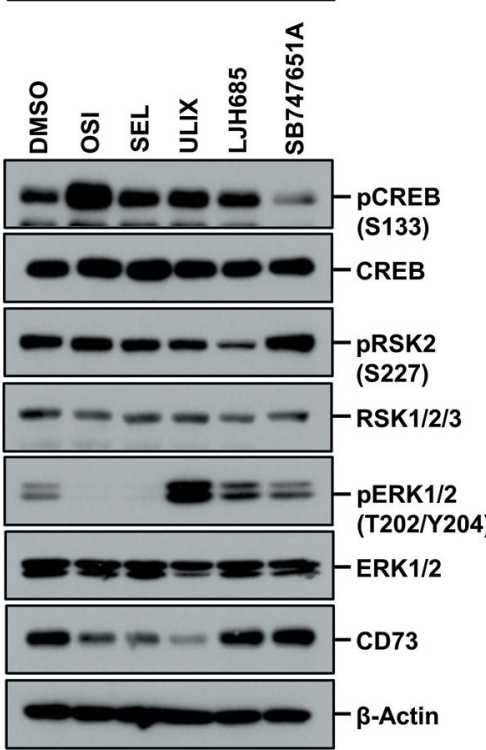

E

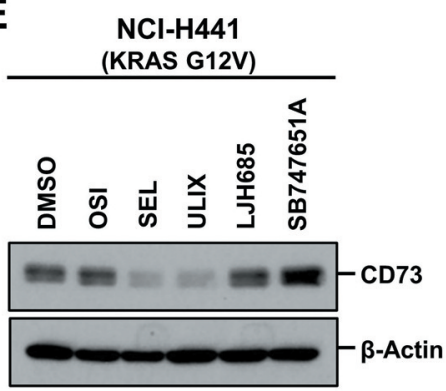

Figure 4. CD73 expression is regulated by ERK1/2 directly without involvement of RSKs or MSKs. (A) Schematic overview of ERK downstream pathways and its inhibitors. (B) qRT-PCR analysis of CD73 mRNA expression in HCC827-, PC-9- and PC-9-AR cells after treatment with ulixertinib (ULIX), LJH685 and SB747651A. GAPDH and $18 S$ served as internal controls. (C) Western blot analysis of CD73 protein expression in HCC827, PC-9- and PC-9-AR cells after treatment with ULIX, LJH685 and SB747651A. $\beta$-Actin served as an internal control. (D) Western blot analysis of CD73 protein expression of HCC827- and PC-9 cells after treatment with GDC-0994. $\beta$-Actin served as internal control. (E) Western blot analysis of CD73 protein expression in $H 441$ cells after treatment with ULIX, LJH685 and SB747651A. $\beta$-Actin served as an internal control. All experiments were carried out in triplicate and data shown represent mean $\pm S D .{ }^{*} p<0.05 ; * p<0.01$, two-tailed Student's t-test. n.s., Not significant.

\section{Discussion}

In this study, we sought to investigate the relationship between EGFR and CD73 in NSCLC. We first found a correlation of EGFR mRNA expression with CD73 mRNA expression in clinical data sets of NSCLC patients (Figure
1A). CD73 expression was significantly elevated in tumors compared to normal lung tissue with EGFR-mutant tumors displaying higher expression than EGFR wildtype tumors (Figure 1B). Next, we observed down-regulation of CD73 mRNA- as well protein expression in EGFR-mutant NSCLC cells when treated with several EGFR TKIs (Figure 2). This 
is the first study to evaluate the importance of EGFR and its downstream signaling pathways in the regulation of CD73 expression in NSCLC. We report that CD73 expression is regulated by the Ras-Raf-ERK pathway in EGFR-mutant as well as KRAS-mutant NSCLC cell lines (Figure 3). Interestingly, inhibition of the PI3K-AKT pathway increased mRNA- and protein expression of CD73, indicating that CD73 is delicately regulated in EGFR-mutant NSCLC. It is generally thought that genes regulated by the Ras-Raf-ERK pathway are involved in cell proliferation and progression, whereas those regulated by the PI3K-AKT pathway mediate cell survival and differentiation. Further studies are warranted to investigate the significance of inhibition of CD73 expression by the PI3K-AKT pathway in NSCLC. Finally, we report that signaling via ERK1/2 directly, without activation of RSKs or MSKs, controls expression of CD73 in both EGFR- and KRAS- mutant cells (Figure 4). The regulation of CD73 mRNA expression by the Ras-Raf-ERK pathway was not the result of altered CD73 mRNA half-life (data not shown), indicating that regulation takes place at the transcriptional level. Transcriptional regulation of CD73 has been previously studied in other cancers and cell entities (49). In cervical cancer cells, CD73 expression was shown to be induced by the Wnt/ $\beta$-Catenin pathway (26) and the $\mathrm{TNF} \alpha / \mathrm{NFkB}$ signaling pathway was reported to regulate CD73 expression in colorectal cancer (27). However, the regulation of basal CD73 expression in NSCLC remains poorly understood. The CD73 promoter has been described as a $201 \mathrm{bp}$ core region upstream of the transcriptional start site (50). Indeed, we found this region to be active in PC-9 cells (data not shown). Interestingly, longer fragments of the CD73 promoter, 969 bp- and 1964 bp- fragments, decreased promoter activity in PC-9 cells, indicating that regulation of CD73 expression in NSCLC is complex and involves both activating as well as inhibiting factors. The $201 \mathrm{bp} \mathrm{CD73}$ core promoter contains several predicted binding sites of transcription factors which are regulated by the Ras-RafERK pathway, such as CREB (51), SP1 (52) and AP-1 (26, 53). In our study, inhibition of MSKs by SB747651A resulted in reduced phosphorylation of CREB, but did not change expression of CD73, indicating that CREB is not involved in the regulation of basal CD73 expression in NSCLC (Figure 4C). To our surprise, activity of the CD73 promoter was not changed upon treatment with selumetinib, suggesting that the Ras-Raf-ERK pathway acts on CD73 expression via other mechanisms (data not shown). It has been reported that c-Jun/AP-1 induces CD73 in melanoma cells by binding to an intronic enhancer (54). Further studies are needed to clarify whether this intronic enhancer is employed by the Ras-Raf-ERK pathway to induce CD73 expression in NSCLC.

In recent years, cancer immunotherapy with antibodies against PD-1 or PD-L1 has been successfully applied in the treatment of several tumors, including NSCLC (55). However, EGFR-mutant NSCLC tumors do not respond well to treatment with these checkpoint inhibitors due to weak immunogenicity (56). PD-L1 has been thought to play a key role in this phenomenon. It has been reported that PD-L1 itself is regulated by EGFR as EGF treatment could induce PD-L1 expression and inhibition of EGFR by EGFR TKI resulted in decrease of PD-L1 expression (57). Moreover, EGFR mutation status is correlated with high PD-L1 expression in NSCLC (58). In contrast, other reports suggest that EGFR-mutant tumors are generally thought to possess low expression of PD-L1, resulting in poor response to checkpoint inhibitor treatment $(59,60)$. Thus, the relationship between EGFR and PD-L1 remains controversial. Regulation of CD73 has been suggested as another possible explanation as to why EGFR-mutant tumors are immunologically "cold". Indeed, herein we report that CD73 expression is regulated by the EGFR pathway in EGFR-mutant NSCLC and that EGFR-mutant tumors display higher CD73 expression than their EGFR wildtype counterparts. However, the prognostic role of high CD73 expression in EGFR-mutant NSCLC when treated with checkpoint inhibitors remains disputed. Ishii et al. recently reported that high CD73 expression may predict a favorable response to checkpoint inhibitors in NSCLC patients; however, the patient cohort analyzed in this study was relatively low (61). Moreover, KRAS-mutant NSCLC were shown to respond rather well to cancer immunotherapy $(62,63)$, despite their association with increased CD73 expression $(40,41)$ and CD73 being regulated by the RasRaf-ERK pathway as shown in this study. In contrast, other studies showed that inhibition of the adenosine pathway increased the efficiency of checkpoint inhibitor therapy in NSCLC patients (64). Future studies are needed to clarify the role of Ras-Raf-ERK-induced CD73 expression in EGFRand KRAS-mutant NSCLC with regard to response to cancer immunotherapy.

Besides its functions in converting extracellular ATP to immunosuppressive adenosine, CD73 also possesses other important functions essential for the survival and proliferation of NSCLC, which are, in part, independent of its enzymatic activity $(16,65)$. It has been reported that knock-down of CD73 inhibits cell growth, cell-cycle progression and migration of KRAS-mutant A549 NSCLC cell line (19). In addition, high CD73 expression was an independent indicator of poor prognosis for overall survival in NSCLC patients (19, 22). We found increased expression of CD73 in PC-9-AR cells which acquired resistance to afatinib by the T790M mutation (Figure 2E). A recent study by Isomoto et al. also showed increased expression of CD73 in NSCLC patients after progression during EGFR-TKI treatment (33), indicating an important role of CD73 in the survival of PC-9-AR cells. It would be intriguing to investigate whether the increase of CD73 expression in PC-9-AR cells indeed contributes to 
resistance to afatinib and thus, represents a novel therapeutic target for the treatment of afatinib-resistant NSCLCs. Currently, inhibition of CD73 by neutralizing antibodies or small-molecule inhibitors has focused on combination therapy with checkpoint inhibitors in the context of cancer immunotherapy $(40,66)$. Given the enzyme activity dependent and -independent functions of CD73 in cancer cell survival and progression, it would be intriguing to test whether CD73 inhibition as monotherapy or in combination with EGFR TKIs could result in a better response in patients with EGFR-mutant NSCLC. Indeed, small-molecule inhibition of CD73 activity has shown promising results in pre-clinical studies of Glioblastoma multiforme (67), warranting future studies on the effectivity and feasibility of CD73 inhibition in NSCLC and other cancers.

\section{Conflicts of Interest}

The Authors declare no conflicts of interest.

\section{Authors' Contributions}

Conceptualization, S.G. and J.C.-H.Y.; investigation, S.G.; methodology, S.G.; data curation, S.G.; formal analysis, S.G.; software, S.G.; visualization, S.G; validation, S.G.; formal analysis, S.G.; resources, J.C.-H.Y.; writing - original draft preparation, S.G.; writing - review and editing, S.G., B-C.L. and J.C.-H.Y..; supervision, J.C.-H.Y.; project administration, J.C.-H.Y. and B-C.L.; funding acquisition, S.G. and B-C.L. All Authors have read and agreed to the published version of the manuscript.

\section{Acknowledgements}

The Authors thank Chia-Chi Hsu (National Taiwan University Cancer Center) for his advice on experimental design and writing the manuscript.

\section{Funding}

The present study was supported by grants from the Ministry of Science and Technology of Taiwan to B.-C.L. (grant number: 1082314-B-002-095-MY3).

\section{References}

1 Shigematsu H and Gazdar AF: Somatic mutations of epidermal growth factor receptor signaling pathway in lung cancers. Int J Cancer 118(2): 257-262, 2006. PMID: 16231326. DOI: 10.1002/ijc. 21496

2 Ono M and Kuwano M: Molecular mechanisms of epidermal growth factor receptor (EGFR) activation and response to gefitinib and other EGFR-targeting drugs. Clin Cancer Res 12(24): 7242-51, 2006. PMID: 17189395. DOI: 10.1158/10780432.CCR-06-0646

3 Mitsudomi T, Morita S, Yatabe Y, Negoro S, Okamoto I, Tsurutani J, Seto T, Satouchi M, Tada H, Hirashima T, Asami K, Katakami
N, Takada M, Yoshioka H, Shibata K, Kudoh S, Shimizu E, Saito H, Toyooka S, Nakagawa K, Fukuoka M and West Japan Oncology Group: Gefitinib versus cisplatin plus docetaxel in patients with non-small-cell lung cancer harbouring mutations of the epidermal growth factor receptor (WJTOG3405): an open label, randomised phase 3 trial. Lancet Oncol 11(2): 121-128, 2010. PMID: 20022809. DOI: 10.1016/S1470-2045(09)70364-X

4 Maemondo M, Inoue A, Kobayashi K, Sugawara S, Oizumi S, Isobe $\mathrm{H}$, Gemma A, Harada M, Yoshizawa H, Kinoshita I, Fujita Y, Okinaga S, Hirano H, Yoshimori K, Harada T, Ogura T, Ando M, Miyazawa H, Tanaka T, Saijo Y, Hagiwara K, Morita S, Nukiwa $T$ and North-East Japan Study Group: Gefitinib or chemotherapy for non-small-cell lung cancer with mutated EGFR. N Engl J Med 362(25): 2380-2388, 2010. PMID: 20573926. DOI: 10.1056/NEJMoa0909530

5 Zhou C, Wu YL, Chen G, Feng J, Liu XQ, Wang C, Zhang S, Wang J, Zhou S, Ren S, Lu S, Zhang L, Hu C, Hu C, Luo Y, Chen L, Ye M, Huang J, Zhi X, Zhang Y, Xiu Q, Ma J, Zhang L and You C: Erlotinib versus chemotherapy as first-line treatment for patients with advanced EGFR mutation-positive non-small-cell lung cancer (OPTIMAL, CTONG-0802): a multicentre, openlabel, randomised, phase 3 study. Lancet Oncol 12(8): 735-742, 2011. PMID: 21783417. DOI: 10.1016/S1470-2045(11)70184-X

6 Wu YL, Zhou C, Hu CP, Feng J, Lu S, Huang Y, Li W, Hou M, Shi JH, Lee KY, Xu CR, Massey D, Kim M, Shi Y and Geater SL: Afatinib versus cisplatin plus gemcitabine for first-line treatment of Asian patients with advanced non-small-cell lung cancer harbouring EGFR mutations (LUX-Lung 6): an openlabel, randomised phase 3 trial. Lancet Oncol 15(2): 213-222, 2014. PMID: 24439929. DOI: 10.1016/S1470-2045(13)70604-1

7 Yang JC, Wu YL, Schuler M, Sebastian M, Popat S, Yamamoto N, Zhou C, Hu CP, O’Byrne K, Feng J, Lu S, Huang Y, Geater SL, Lee KY, Tsai CM, Gorbunova V, Hirsh V, Bennouna J, Orlov S, Mok T, Boyer M, Su WC, Lee KH, Kato T, Massey D, Shahidi M, Zazulina V and Sequist LV: Afatinib versus cisplatinbased chemotherapy for EGFR mutation-positive lung adenocarcinoma (LUX-Lung 3 and LUX-Lung 6): analysis of overall survival data from two randomised, phase 3 trials. Lancet Oncol 16(2): 141-151, 2015. PMID: 25589191. DOI: 10.1016/S1470-2045(14)71173-8

8 Schadendorf D, Hodi F, Robert C, Weber J, Margolin K, Hamid O, Patt D, Chen T, Berman D and Wolchok J: Pooled analysis of long-term survival data from phase II and phase III trials of ipilimumab in unresectable or metastatic melanoma. Journal of Clinical Oncology 33(17): 1889-1894, 2020. DOI: 10.1200/ JCO.2014.56.2736

9 Topalian S, Hodi F, Brahmer J, Gettinger S, Smith D, Mcdermott D, Powderly J, Sosman J, Atkins M, Leming P, Spigel D, Antonia S, Drilon A, Wolchok J, Carvajal R, Mchenry M, Hosein F, Harbison C, Grosso J and Sznol M: Five-year survival and correlates among patients with advanced melanoma, renal cell carcinoma, or non-small cell lung cancer treated with nivolumab. JAMA Oncology 5(10): 1411, 2019. DOI: 10.1001/jamaoncol.2019.2187

10 Lee C, Man J, Lord S, Cooper W, Links M, Gebski V, Herbst $\mathrm{R}$, Gralla R, Mok $\mathrm{T}$ and Yang J: Clinical and molecular characteristics associated with survival among patients treated with checkpoint inhibitors for advanced non-small cell lung carcinoma. JAMA Oncology 4(2): 210, 2018. DOI: 10.1001/jamaoncol.2017.4427 
11 Rittmeyer A, Barlesi F, Waterkamp D, Park K, Ciardiello F, Von pawel J, Gadgeel S, Hida T, Kowalski D, Dols M, Cortinovis D, Leach J, Polikoff J, Barrios C, Kabbinavar F, Frontera O, De marinis F, Turna H, Lee J, Ballinger M, Kowanetz M, He P, Chen D, Sandler A and Gandara D: Atezolizumab versus docetaxel in patients with previously treated non-small-cell lung cancer $(\mathrm{OAK})$ : a phase 3 , open-label, multicentre randomised controlled trial. The Lancet 389(10066): 255-265, 2019. DOI: 10.1016/S0140-6736(16)32517-X

12 Dong Z, Zhang J, Liu S, Su J, Zhang C, Xie Z, Zhou Q, Tu H, $\mathrm{Xu}$ C, Yan L, Li Y, Zhong W and Wu Y: EGFR mutation correlates with uninflamed phenotype and weak immunogenicity, causing impaired response to PD-1 blockade in non-small cell lung cancer. OncoImmunology 6(11): e1356145, 2017. DOI: $10.1080 / 2162402 X .2017 .135614$

13 Offin M, Rizvi H, Tenet M, Ni A, Sanchez-vega F, Li B, Drilon A, Kris M, Rudin C, Schultz N, Arcila M, Ladanyi M, Riely G, $\mathrm{Yu} \mathrm{H}$ and Hellmann M: Tumor mutation burden and efficacy of egfr-tyrosine kinase inhibitors in patients with EGFR-mutant lung cancers. Clinical Cancer Research 25(3): 1063-1069, 2020. DOI: $10.1158 / 1078-0432 . C C R-18-1102$

14 Linden J and Cekic C: Regulation of lymphocyte function by adenosine. Arteriosclerosis, thrombosis, and vascular biology 32(9): 2097-2103, 2018. DOI: 10.1161/ATVBAHA.111.226837

15 Allard B, Allard D, Buisseret L and Stagg J: The adenosine pathway in immuno-oncology. Nature Reviews Clinical Oncology 17(10): 611-629, 2020. DOI: 10.1038/s41571-020-0382-2

16 Gao Z, Wang H, Lin F, Wang X, Long M, Zhang H and Dong $\mathrm{K}$ : CD73 promotes proliferation and migration of human cervical cancer cells independent of its enzyme activity. BMC Cancer 17(1): 135, 2019. DOI: 10.1186/s12885-017-3128-5

17 Wu R, Chen Y, Li F, Li W, Zhou H, Yang Y and Pei Z: Effects of CD73 on human colorectal cancer cell growth in vivo and in vitro. Oncol Rep 35(3): 1750-1756, 2016. PMID: 26708311. DOI: $10.3892 /$ or.2015.4512

18 Zhou L, Jia S, Chen Y, Wang W, Wu Z, Yu W, Zhang M, Ding $\mathrm{G}$ and Cao L: The distinct role of CD73 in the progression of pancreatic cancer. Journal of Molecular Medicine 97(6): 803815, 2020. DOI: 10.1007/s00109-018-01742-0

19 Zhu J, Zeng Y, Li W, Qin H, Lei Z, Shen D, Gu D, Huang J and Liu $\mathrm{Z}$ : CD73/NT5E is a target of miR-30a-5p and plays an important role in the pathogenesis of non-small cell lung cancer. Molecular Cancer 16(1): 34, 2019. DOI: 10.1186/s12943-017-0591-1

20 Ma X, Shen M, Hu B, Wang B, Yang W, Lv L, Wang H, Zhou Y, Jin A, Sun Y, Zhang C, Qiu S, Pan B, Zhou J, Fan J, Yang X and Guo W: CD73 promotes hepatocellular carcinoma progression and metastasis via activating PI3K/AKT signaling by inducing Rap1-mediated membrane localization of P110 $\beta$ and predicts poor prognosis. Journal of Hematology \& Oncology 12(1): 37, 2020. DOI: 10.1186/s13045-019-0724-7

21 Xu Z, Gu C, Yao X, Guo W, Wang H, Lin T, Li F, Chen D, Wu J, Ye G, Zhao L, Hu Y, Yu J, Shi J, Li G and Liu H: CD73 promotes tumor metastasis by modulating RICS/RhoA signaling and EMT in gastric cancer. Cell Death \& Disease 11(3): 202, 2020. DOI: $10.1038 / \mathrm{s} 41419-020-2403-6$

22 Inoue Y, Yoshimura K, Kurabe N, Kahyo T, Kawase A, Tanahashi M, Ogawa H, Inui N, Funai K, Shinmura K, Niwa H, Suda T and Sugimura H: Prognostic impact of CD73 and A2A adenosine receptor expression in non-small-cell lung cancer. Oncotarget $8(5)$ : 8738-8751, 2020. DOI: 10.18632/oncotarget.14434
23 Jiang T, Xu X, Qiao M, Li X, Zhao C, Zhou F, Gao G, Wu F, Chen X, Su C, Ren S, Zhai C and Zhou C: Comprehensive evaluation of NT5E/CD73 expression and its prognostic significance in distinct types of cancers. BMC Cancer 18(1): 267, 2020. DOI: 10.1186/s12885-018-4073-7

24 Roh M, Wainwright D, Wu J, Wan Y and Zhang B: Targeting CD73 to augment cancer immunotherapy. Current Opinion in Pharmacology 53: 66-76, 2020. DOI: 10.1016/j.coph.2020.07.001

25 Synnestvedt K, Furuta GT, Comerford KM, Louis N, Karhausen J, Eltzschig HK, Hansen KR, Thompson LF and Colgan SP: Ecto-5'-nucleotidase (cd73) regulation by hypoxia-inducible factor-1 mediates permeability changes in intestinal epithelia. J Clin Invest 110(7): 993-1002, 2002. PMID: 12370277. DOI: 10.1172/JCI15337

26 Spychala $\mathrm{J}$ and Kitajewski J: Wnt and beta-catenin signaling target the expression of ecto-5'-nucleotidase and increase extracellular adenosine generation. Exp Cell Res 296(2): 99-108, 2004. PMID: 15149841. DOI: 10.1016/j.yexcr.2003.11.001

27 Pagnotta S, Laudanna C, Pancione M, Sabatino L, Votino C, Remo A, Cerulo L, Zoppoli P, Manfrin E, Colantuoni V and Ceccarelli M: Ensemble of gene signatures identifies novel biomarkers in colorectal cancer activated through PPAR $\gamma$ and TNFa signaling. PLoS ONE 8(8): e72638, 2018. DOI: 10.1371/journal.pone. 0072638

28 Selamat S, Chung B, Girard L, Zhang W, Zhang Y, Campan M, Siegmund K, Koss M, Hagen J, Lam W, Lam S, Gazdar A and Laird-offringa I: Genome-scale analysis of DNA methylation in lung adenocarcinoma and integration with mRNA expression. Genome Research 22(7): 1197-1211, 2017. DOI: 10.1101/ gr.132662.111

29 Barretina J, Caponigro G, Stransky N, Venkatesan K, Margolin A, Kim S, Wilson C, Lehár J, Kryukov G, Sonkin D, Reddy A, Liu M, Murray L, Berger M, Monahan J, Morais P, Meltzer J, Korejwa A, Jané-valbuena J, Mapa F, Thibault J, Bric-furlong E, Raman P, Shipway A, Engels I, Cheng J, Yu G, Yu J, Aspesi $\mathrm{P}$, De silva M, Jagtap K, Jones M, Wang L, Hatton C, Palescandolo E, Gupta S, Mahan S, Sougnez C, Onofrio R, Liefeld T, Macconaill L, Winckler W, Reich M, Li N, Mesirov J, Gabriel S, Getz G, Ardlie K, Chan V, Myer V, Weber B, Porter J, Warmuth M, Finan P, Harris J, Meyerson M, Golub T, Morrissey M, Sellers W, Schlegel R and Garraway L: The cancer cell line encyclopedia enables predictive modelling of anticancer drug sensitivity. Nature 483(7391): 603-607, 2020. DOI: $10.1038 /$ nature 11003

30 Baselga J and Averbuch SD: ZD1839 ('Iressa') as an anticancer agent. Drugs 60 Suppl 1: 33-40; discussion 41-2, 2000. PMID: 11129170. DOI: 10.2165/00003495-200060001-00004

31 Li D, Ambrogio L, Shimamura T, Kubo S, Takahashi M, Chirieac L, Padera R, Shapiro G, Baum A, Himmelsbach F, Rettig W, Meyerson M, Solca F, Greulich H and Wong K: BIBW2992, an irreversible EGFR/HER2 inhibitor highly effective in preclinical lung cancer models. Oncogene 27(34): 4702-4711, 2019. DOI: 10.1038/onc 2008.109

32 Finlay MR, Anderton M, Ashton S, Ballard P, Bethel PA, Box MR, Bradbury RH, Brown SJ, Butterworth S, Campbell A, Chorley C, Colclough N, Cross DA, Currie GS, Grist M, Hassall L, Hill GB, James D, James M, Kemmitt P, Klinowska T, Lamont G, Lamont SG, Martin N, McFarland HL, Mellor MJ, Orme JP, Perkins D, Perkins P, Richmond G, Smith P, Ward RA, Waring MJ, Whittaker D, Wells S and Wrigley GL: Discovery 
of a potent and selective EGFR inhibitor (AZD9291) of both sensitizing and T790M resistance mutations that spares the wild type form of the receptor. J Med Chem 57(20): 8249-8267, 2014. PMID: 25271963. DOI: 10.1021/jm500973a

33 Isomoto K, Haratani K, Hayashi H, Shimizu S, Tomida S, Niwa T, Yokoyama T, Fukuda Y, Chiba Y, Kato R, Tanizaki J, Tanaka $\mathrm{K}$, Takeda M, Ogura T, Ishida T, Ito A and Nakagawa K: Impact of EGFR-TKI treatment on the tumor immune microenvironment in EGFR mutation-positive non-small cell lung cancer. Clin Cancer Res 26(8): 2037-2046, 2020. PMID: 31937613. DOI: 10.1158/1078-0432.CCR-19-2027

34 Logue J and Morrison D: Complexity in the signaling network: insights from the use of targeted inhibitors in cancer therapy. Genes \& Development 26(7): 641-650, 2017. DOI: 10.1101/ gad.186965.112

$35 \mathrm{Wu}$ P and Park J: MEK1/2 Inhibitors: Molecular Activity and Resistance Mechanisms. Seminars in Oncology 42(6): 849-862, 2019. DOI: 10.1053/j.seminoncol.2015.09.023

36 Pal S, Reckamp K, Yu H and Figlin R: Akt inhibitors in clinical development for the treatment of cancer. Expert Opinion on Investigational Drugs 19(11): 1355-1366, 2020. DOI: 10.1517/13543784.2010.520701

37 Verstovsek S: Therapeutic potential of JAK2 inhibitors. Hematology 2009(1): 636-642, 2020. PMID: 20008249 DOI: 10.1182/asheducation-2009.1.636

38 Ye X, Chan K, Waters A, Bess M, Harned A, Wei B, Loncarek J, Luke B, Orsburn B, Hollinger B, Stephens R, Bagni R, Martinko A, Wells J, Nissley D, Mccormick F, Whiteley G and Blonder J: Comparative proteomics of a model MCF10AKRasG12V cell line reveals a distinct molecular signature of the KRasG12V cell surface. Oncotarget 7(52): 86948-86971, 2020. DOI: 10.18632/oncotarget.13566

39 Tahir R, Renuse S, Udainiya S, Madugundu AK, Cutler JA, Nirujogi RS, Na CH, Xu Y, Wu X and Pandey A: Mutationspecific and common phosphotyrosine signatures of KRAS G12D and G13D alleles. J Proteome Res 20(1): 670-683, 2021. PMID: 32986951. DOI: 10.1021/acs.jproteome.0c00587

40 Harvey J, Phan L, Villarreal O and Bowser J: CD73's Potential as an Immunotherapy Target in Gastrointestinal Cancers. Frontiers in Immunology 11: 508, 2020. DOI: 10.3389/fimmu. 2020.00508

41 Salazar RS, Solorzano J, Solis L, Behrens C, Mino B, Parra E, Zhang J, Vaporciyan A, Rice D, Kalhor N, Moran C, Gibbons D, Weissferdt A, Sepesi B and Wistuba I: Cd73 immunohistochemical expression in malignant cells and correlation with immune infiltrate in non-small cell lung carcinoma (nsclc). J Thorac Oncol 13(10): S533-S534, 2018.

42 Frödin $\mathrm{M}$ and Gammeltoft $\mathrm{S}$ : Role and regulation of $90 \mathrm{kDa}$ ribosomal S6 kinase (RSK) in signal transduction. Mol Cell Endocrinol 151(1-2): 65-77, 1999. PMID: 10411321. DOI: 10.1016/s0303-7207(99)00061-1

43 Germann UA, Furey BF, Markland W, Hoover RR, Aronov AM, Roix JJ, Hale M, Boucher DM, Sorrell DA, Martinez-Botella G, Fitzgibbon M, Shapiro P, Wick MJ, Samadani R, Meshaw K, Groover A, DeCrescenzo G, Namchuk M, Emery CM, Saha S and Welsch DJ: Targeting the MAPK signaling pathway in cancer: Promising preclinical activity with the novel selective ERK1/2 inhibitor BVD-523 (Ulixertinib). Mol Cancer Ther 16(11): 2351-2363, 2017. PMID: 28939558. DOI: 10.1158/15357163.MCT-17-0456
44 Aronchik I, Appleton BA, Basham SE, Crawford K, Del Rosario M, Doyle LV, Estacio WF, Lan J, Lindvall MK, Luu CA, Ornelas E, Venetsanakos E, Shafer CM and Jefferson AB: Novel potent and selective inhibitors of p90 ribosomal S6 kinase reveal the heterogeneity of RSK function in MAPK-driven cancers. Mol Cancer Res 12(5): 803-812, 2014. PMID: 24554780. DOI: 10.1158/1541-7786.MCR-13-0595

45 Naqvi S, Macdonald A, McCoy CE, Darragh J, Reith AD and Arthur JS: Characterization of the cellular action of the MSK inhibitor SB-747651A. Biochem J 441(1): 347-357, 2012. PMID: 21970321. DOI: 10.1042/BJ20110970

46 Blake JF, Burkard M, Chan J, Chen H, Chou KJ, Diaz D, Dudley DA, Gaudino JJ, Gould SE, Grina J, Hunsaker T, Liu L, Martinson M, Moreno D, Mueller L, Orr C, Pacheco P, Qin A, Rasor K, Ren L, Robarge K, Shahidi-Latham S, Stults J, Sullivan F, Wang W, Yin J, Zhou A, Belvin M, Merchant M, Moffat J and Schwarz JB: Discovery of (S)-1-(1-(4-Chloro-3fluorophenyl)-2-hydroxyethyl)-4-(2-((1-methyl-1H-pyrazol-5yl)amino)pyrimidin-4-yl)pyridin-2(1H)-one (GDC-0994), an Extracellular Signal-Regulated Kinase 1/2 (ERK1/2) Inhibitor in Early Clinical Development. J Med Chem 59(12): 56505660, 2016. PMID: 27227380. DOI: 10.1021/acs.jmedchem. $6 \mathrm{~b} 00389$

47 Ekerot M, Stavridis M, Delavaine L, Mitchell M, Staples C, Owens D, Keenan I, Dickinson R, Storey K and Keyse S: Negative-feedback regulation of FGF signalling by DUSP6/ MKP-3 is driven by ERK1/2 and mediated by Ets factor binding to a conserved site within the DUSP6/MKP-3 gene promoter. Biochemical Journal 412(2): 287-298, 2019. DOI: 10.1042/BJ20 071512

48 Treisman R: Journey to the surface of the cell: Fos regulation and the sre. EMBO J 14(20): 4905-4913, 1995. PMID: 7588619.

49 Kordaß T, Osen W and Eichmüller S: Controlling the immune suppressor: Transcription factors and microRNAs regulating CD73/NT5E. Frontiers in Immunology 9:813, 2019. DOI: 10.3389/fimmu.2018.00813

50 Spychala J, Zimmermann AG and Mitchell BS: Tissue-specific regulation of the ecto-5'-nucleotidase promoter. Role of the camp response element site in mediating repression by the upstream regulatory region. J Biol Chem 274(32): 22705-22712, 1999. PMID: 10428853. DOI: 10.1074/jbc.274.32.22705

51 Arthur JS: MSK activation and physiological roles. Front Biosci 13: 5866-79, 2008. PMID: 18508628. DOI: $10.2741 / 3122$

52 Merchant JL, Du M and Todisco A: Sp1 phosphorylation by Erk 2 stimulates DNA binding. Biochem Biophys Res Commun 254(2): 454-461, 1999. PMID: 9918860. DOI: 10.1006/bbrc.1998.9964

53 Whitmarsh AJ and Davis RJ: Transcription factor AP-1 regulation by mitogen-activated protein kinase signal transduction pathways. J Mol Med (Berl) 74(10): 589-607, 1996. PMID: 8912180. DOI: 10.1007/s001090050063

54 Reinhardt J, Landsberg J, Schmid-burgk J, Ramis B, Bald T, Glodde N, Lopez-ramos D, Young A, Ngiow S, Nettersheim D, Schorle H, Quast T, Kolanus W, Schadendorf D, Long G, Madore J, Scolyer R, Ribas A, Smyth M, Tumeh P, Tüting T and Hölzel M: MAPK signaling and inflammation link melanoma phenotype switching to induction of CD73 during immunotherapy. Cancer Research 77(17): 4697-4709, 2020. DOI: $10.1158 / 0008-5472 . C A N-17-0395$

55 Sgambato A, Casaluce F and Gridelli C: The role of checkpoint inhibitors immunotherapy in advanced non-small cell lung 
cancer in the elderly. Expert Opin Biol Ther 17(5): 565-571, 2017. PMID: 28276698. DOI: 10.1080/14712598.2017.1294157

56 Jin R, Zhao J, Xia L, Li Q, Li W, Peng L and Xia Y: Application of immune checkpoint inhibitors in EGFR-mutant non-small-cell lung cancer: from bed to bench. Therapeutic Advances in Medical Oncology 12: 175883592093033, 2020. DOI: $10.1177 / 1758835920930333$

57 Chen N, Fang W, Zhan J, Hong S, Tang Y, Kang S, Zhang Y, He X, Zhou T, Qin T, Huang Y, Yi X and Zhang L: Upregulation of PD-L1 by EGFR activation mediates the immune escape in EGFR-driven NSCLC: Implication for optional immune targeted therapy for NSCLC patients with EGFR mutation. J Thorac Oncol 10(6): 910-923, 2015. PMID: 25658629. DOI: 10.1097/JTO.0000000000000500

58 Azuma K, Ota K, Kawahara A, Hattori S, Iwama E, Harada T, Matsumoto K, Takayama K, Takamori S, Kage M, Hoshino T, Nakanishi Y and Okamoto I: Association of PD-L1 overexpression with activating EGFR mutations in surgically resected nonsmallcell lung cancer. Ann Oncol 25(10): 1935-1940, 2014. PMID: 25009014. DOI: 10.1093/annonc/mdu242

59 Ji M, Liu Y, Li Q, Li X, Ning Z, Zhao W, Shi H, Jiang J and Wu C: PD-1/PD-L1 expression in non-small-cell lung cancer and its correlation with EGFR/KRAS mutations. Cancer Biology \& Therapy 17(4): 407-413, 2020. DOI: 10.1080/15384047. 2016.1156256

60 Soo RA, Lim SM, Syn NL, Teng R, Soong R, Mok TSK and Cho BC: Immune checkpoint inhibitors in epidermal growth factor receptor mutant non-small cell lung cancer: Current controversies and future directions. Lung Cancer 115: 12-20, 2018. PMID: 29290252. DOI: 10.1016/j.lungcan.2017.11.009

61 Ishii H, Azuma K, Kawahara A, Kinoshita T, Matsuo N, Naito Y, Tokito T, Yamada K, Akiba J and Hoshino T: Predictive value of CD73 expression for the efficacy of immune checkpoint inhibitors in NSCLC. Thoracic Cancer 11(4): 950-955, 2020. DOI: $10.1111 / 1759-7714.13346$
62 Liu C, Zheng S, Jin R, Wang X, Wang F, Zang R, Xu H, Lu Z, Huang J, Lei Y, Mao S, Wang Y, Feng X, Sun N, Wang Y and $\mathrm{He} \mathrm{J}$ : The superior efficacy of anti-PD-1/PD-L1 immunotherapy in KRAS-mutant non-small cell lung cancer that correlates with an inflammatory phenotype and increased immunogenicity. Cancer Lett 470: 95-105, 2020. PMID: 31644929. DOI: $10.1016 /$ j.canlet.2019.10.027

63 Torralvo J, Friedlaender A, Achard V and Addeo A: The Activity of immune checkpoint inhibition in KRAS mutated non-small cell lung cancer: A single centre experience. Cancer Genomics - Proteomics 16(6): 577-582, 2020. DOI: 10.21873/cgp.20160

64 Beavis PA, Milenkovski N, Henderson MA, John LB, Allard B, Loi S, Kershaw MH, Stagg J and Darcy PK: Adenosine receptor 2A blockade increases the efficacy of anti-PD-1 through enhanced antitumor T-cell responses. Cancer Immunol Res 3(5): 506-517, 2015. PMID: 25672397. DOI: 10.1158/2326-6066.CIR-14-0211

65 Zhi X, Chen S, Zhou P, Shao Z, Wang L, Ou Z and Yin L: RNA interference of ecto-5'-nucleotidase (CD73) inhibits human breast cancer cell growth and invasion. Clin Exp Metastasis 24(6): 439-448, 2007. PMID: 17587186. DOI: 10.1007/s10585007-9081-y

66 Jeffrey JL, Lawson KV and Powers JP: Targeting metabolism of extracellular nucleotides via inhibition of ectonucleotidases CD73 and CD39. J Med Chem 63(22): 13444-13465, 2020. PMID: 32786396. DOI: 10.1021/acs.jmedchem.0c01044

67 Figueiró F, Mendes FB, Corbelini PF, Janarelli F, Jandrey EH, Russowsky D, Eifler-Lima VL and Battastini AM: A monastrolderived compound, LaSOM 63, inhibits ecto-5' nucleotidase/CD73 activity and induces apoptotic cell death of glioma cell lines. Anticancer Res 34(4): 1837-1842, 2014. PMID: 24692717.

Received January 12, 2021

Revised January 28, 2021

Accepted February 8, 2021 